\title{
Isolation of DNA Markers from a Region between Incontinentia Pigmenti 1 (IP1) X-Chromosomal Translocation Breakpoints by a Comparative PCR Analysis of a Radiation Hybrid Subclone Mapping Panel
}

\author{
Jerome L. Gorski, ${ }^{*} \dagger,{ }^{1}$ ERIC N. BURright, $†$ Eric L. ReYNer, $\dagger$ \\ Peter N. Goodfellow, $¥$ and Daniel L. Burgess $†$
}

*Departments of Pediatrics and Communicable Diseases and tHuman Genetics, University of Michigan, Ann Arbor, Michigan 48109; and $\ddagger$ Imperial Cancer Research Fund, P.O. Box 123, Lincoln's Inn Fields, London WC2A 3PX, United Kingdom

Received March 18, 1992; revised July 27, 1992

\begin{abstract}
A strategy based on the use of human-specific interspersed repetitive sequence (IRS)-PCR amplification was used to isolate regional DNA markers in the vicinity of the incontinentia pigmenti 1 (IP1) locus. A radiation hybrid ( $\mathrm{RH})$ resulting from a fusion of an irradiated X-only somatic cell hybrid (C12D) and a thymidine kinase deficient (TK-) hamster cell line (a23) was identified as containing multiple $X$ chromosome fragments, including DNA markers spanning IP1 X-chromosomal translocation breakpoints within region Xp11.21. From this RH, a panel of subclones was constructed and analyzed by IRS-PCR amplification to (a) identify subclones containing a reduced number of $X$ chromosome fragments spanning the IP1 breakpoints and (b) construct a mapping panel to assist in identifying regional DNA markers in the vicinity of the IP1 locus. By using this strategy, we have isolated three different IRS-PCR amplification products that map to a region between IP1 $X$ chromosome translocation breakpoints. A total of nine DNA sequences have now been mapped to this region; using these DNA markers for PFGE analyses, we obtained a probe order DXS14DXS422-MTHFDL1-DXS705. These DNA markers provide a starting point for identifying overlapping genomic sequences spanning the IP1 translocation breakpoints; the availability of IP1 translocation breakpoints should assist the molecular analysis of this locus. (1992 Academic Press, Inc.
\end{abstract}

\section{INTRODUCTION}

The isolation of DNA markers from a targeted chromosomal region has been a required prerequisite for the positional cloning of human genes and the construction

\footnotetext{
${ }^{1}$ To whom correspondence and reprint requests should be addressed at Division of Pediatric Genetics, Department of Pediatrics, 3570 MSRB II, P.O. Box 0688, University of Michigan Medical Center, Ann Arbor, MI 48109-0688.
}

of complete regional maps. In addition, the construction and characterization of somatic cell hybrids containing defined human chromosomal fragments has been instrumental in the development of high-resolution physical maps. As part of an effort to clone the incontinentia pigmenti 1 (IP1) locus, we sought a strategy to increase the efficiency of isolating region-specific DNA markers from Xp11.21. The IP1 locus has been mapped to region Xp11.21 by cytologic (Gilgenkrantz et al., 1985; Hodgson et al., 1985; Kajii et al., 1985; Cannizzaro and Hecht, 1987; Crolla et al., 1989) and molecular (Gorski et al., 1991) analyses.

A three-step approach was taken to isolate additional regional DNA markers in the vicinity of the IP1 locus. First, radiation hybrids (RHs) that contained DNA markers spanning IP1 X-chromosomal translocation breakpoints were identified. $\mathrm{RH}$ s have been shown to be an effective means of nonselectively retaining small defined human chromosome fragments (Benham et al., 1989; Cox et al., 1989; Zoghbi et al., 1991). Second, to further enrich for DNA markers in the vicinity of the IP1 locus and construct a RH mapping panel, a single $\mathrm{RH}$ containing markers spanning the IP1 breakpoints was used to isolate $\mathrm{RH}$ subclones. We hypothesized that, for a $\mathrm{RH}$ containing multiple human chromosomal fragments, fragments integrated within different hamster chromosomes would segregate independently during passage. By inference this suggested that, by isolating and characterizing a number of $\mathrm{RH}$ subclones, it would be possible to (a) identify "enriched" subclones that nonselectively retained DNA markers in the vicinity of the IP1 locus while losing other human fragments present in the parental $\mathrm{RH}$, (b) determine whether DNA markers consistently cosegregated as expected for markers present on a single integrated fragment, and (c) use the $\mathrm{RH}$ subclones to construct a regional mapping panel.

Third, RH subclones were analyzed by using interspersed repetitive sequence (IRS)-PCR amplification; 
by using primers directed against human repetitive sequences, it is possible to selectively amplify human-specific DNA sequences (Nelson et al., 1989; Ledbetter et al., 1990). Here, IRS-PCR amplification was used to "fingerprint" $\mathrm{RH}$ subclones, estimate the complexity of the human DNA contained within each hybrid, and generate new DNA markers. To facilitate the latter task, a comparative analysis was performed to identify and isolate IRS-PCR products restricted to $\mathrm{RH}$ subclones containing DNA markers spanning IP1 breakpoints. IRSPCR products were mapped to specific intervals within Xp11.21 by using an IP1 somatic cell hybrid mapping panel (Gorski et al., 1991) and were used as probes to extend the physical map of the IP1 locus.

\section{MATERIALS AND METHODS}

Somatic cell hybrid and radiation hybrid cell lines. C9-5, B13-3, and C17-1D3 are human-hamster hybrid cell lines and CLX17-A12 is a human-mouse hybrid cell line constructed from Epstein-Barr virustransformed lymphoblastoid cell lines derived from three unrelated female patients with nonfamilial IP. Hybrids C9-5 and B13-3 contain the translocated X chromosome $t(X ; 9)(p 11.21 ; q 34.3)$ (Gilgenkrantz et al., 1985) and t(X;13)(p11.21; q12.3) (Kajii et al., 1985), respectively; hybrid C17-1D3 contains the derivative $\mathrm{X}$ chromosome, and hybrid CLX17-A12 contains the derivative 17 chromosome $t(X ; 17)$ (p11;p11) (Hodgson et al., 1985; Crolla et al., 1989). The construction and characterization of these hybrids has been described (Gorski et al., 1989, 1991). Hybrids GM06853 and GM06318 contain only a structurally intact human X chromosome (Coriell Medical Institute, Camden, $\mathrm{NJ})$. Hybrid A63-1A contains the translocation chromosome $t(\mathrm{X} ; 20)(20$ pter-q11.1::Xq11.1-xqter); hybrid A48-1Fa contains the translocation chromosome t(X;11)(11pter-11cen::Xcen-Xqter) (Mahtani and Willard, 1988); and hybrid GM10501 contains the translocation chromosome $\mathrm{t}(\mathrm{X} ; 17)(17 \mathrm{qter}-17 \mathrm{q} 11.2:: \mathrm{Xp} 11.21-\mathrm{Xqter})$ (Lafreniere et al., 1991) (Coriell Medical Institute).

A procedure to produce radiation hybrids has been described in detail (Benham et al., 1989). Briefly, RHs containing portions of a human X chromosome were constructed by irradiating a human-hamster hybrid cell line containing a single structurally intact human $\mathrm{X}$ chromosome, C12D (Goss and Harris, 1975), with 50,000 rads and performing a polyethylene glycol-mediated fusion with thymidine kinase deficient (TK-) hamster cell line a23 (Westerveld et al., 1971). $\mathrm{RH}$ s were screened by hybridization analysis using 32 randomly distributed DNA markers that spanned the length of the $\mathrm{X}$ chromosome including markers mapped immediately proximal (DXZ1, Xcen) and distal (DXS146, Xp11.22) to and between (DXS14, Xp11.21) IP1 Xchromosomal translocation breakpoints (Gorski et al., 1991, 1992). RH clone 128 (RH 128) was one of 4 RHs identified which contained these 3 loci and less than 3 other X-chromosomal loci. RH 128 alone was found to survive prolonged passage. $\mathrm{RH} 128$ subclones were obtained by dilutional subcloning; each clone was isolated from a separate plate.

PCR amplification and analysis. Three different primers directed against Alu (Nelson et al., 1989) or L1Hs (Ledbetter et al., 1990) human-specific consensus sequences were modified to contain a $5^{\prime}$ $N o t \mathrm{I}$ restriction endonuclease recognition sequence; these included the 5 ' Alu consensus sequence A-517N, AAGTGCGGCCGCGATCTCGGCTCACTGCAA; the $3^{\prime}$ Alu consensus sequence A-TC65N, AAGTCGCGGCCGCTTGCAGTGAGCCGAGAT; and the L1Hs consensus sequence L1HsN, AAGTCGCGGCCGCATGGCACATGTATACATATGTAACT/AAACC. PCR was performed in a 100- $\mu \mathrm{l}$ volume containing $1 \mu \mathrm{g}$ of hybrid DNA, $50 \mathrm{mM} \mathrm{KCl,} 10 \mathrm{mM}$ Tris-HCl, $1.6 \mathrm{mM} \mathrm{MgCl} 2,0.01 \%$ gelatin, $250 \mu M$ each dNTPs, and either $0.5 \mu M$ (A-517N, A-TC65N) or $1 \mu M(\mathrm{~L} 1 \mathrm{HsN})$ primer. PCR reactions were incubated at $37^{\circ} \mathrm{C}$ for $1 \mathrm{~h}, 94^{\circ} \mathrm{C}$ for $9 \mathrm{~min}$, and, after the addition of $5 \mathrm{U}$ AmpliTaq DNA polymerase (Perkin-Elmer/Cetus), 36 cycles of $94^{\circ} \mathrm{C}$ denaturation $(1 \mathrm{~min}), 55^{\circ} \mathrm{C}$ annealing $(1 \mathrm{~min})$, and $72^{\circ} \mathrm{C}$ extension $(4$ $\mathrm{min}$ ) were performed. Amplification products were electrophoresed in $1.5 \%$ agarose and stained with ethidium bromide; single PCR products were excised from a gel, electroluted, and purified by diethylaminoethyl cellulose chromatography (DE52; Whatman, UK) (Schleif and Wensink, 1981). Gel-purified and subcloned amplification products were reamplified by using $1 \mathrm{ng}$ of product and the original primer. To identify unique amplification products, like-sized products were digested with either RsaI or AluI and electrophoresed in 1.5\% agarose; products yielding a unique pattern of restriction fragments ("fingerprint") were selected for further characterization. For subcloning, PCR products were sequentially extracted with phenol and chloroform, digested with restriction enzyme NotI, reextracted, and ligated to NotI-digested plasmid.

DNA probes. DNA markers used in this study have been previously described (Gorski et al., 1991). The localization of these markers relative to IP1 X-chromosomal translocation breakpoints is shown schematically in Fig. 2 and summarized in a companion paper (Gorski et al., 1992). Plasmid DNA was prepared by standard techniques; prior to use as probes, DNA fragments were isolated from agarose gels by electrolution (Maniatis et al., 1982).

Standard and pulsed-field Southern hybridizations. Standard and pulsed-field Southern transfer hybridizations were performed as described (Gorski et al., 1991, 1992). Radioactive probes were prepared by random oligonucleotide priming (Feinberg and Vogelstein, 1983) PCR amplification products to be used as probes were preannealed with human placental DNA to $C_{0} t 100$ as described (Sealey et al., 1985). $\mathrm{PFGE}$ was performed at $14^{\circ} \mathrm{C}$ in $0.5 \times \mathrm{TBE}$ buffer (Maniatis $e t$ $a l$., 1982) using a contour-clamped homogeneous electrical field (CHEF) gel system (Chu et al., 1986) (CHEF DRII, Bio-Rad).

\section{RESULTS}

\section{Identification and Characterization of Radiation Hybrids}

Radiation hybrid 128 (RH 128) was found to contain at least five different loci in the vicinity of the IP1 locus, including loci mapped proximal (DXZ1; Xcen) and distal (DXS146; Xp11.22) to and between (DXS14, DXS343, DXS370; Xp11.21) IP1 X-chromosomal translocation breakpoints (Gorski et al., 1991) (Fig. 1); these results suggested that RH 128 contained an Xchromosomal fragment spanning the IP1 translocation breakpoints. RH 128 did not contain flanking loci DXS7 (Xp11.3) or DXS1 (Xq11) (data not shown). Using an additional 30 probes randomly distributed along the length of the $\mathrm{X}$ chromosome, including 22 probes mapped to $\mathrm{Xq}$, hybridization analyses showed that $\mathrm{RH}$ 128 contained only two additional loci mapped to Xp22.3 (DXYS20 and STS) (data not shown).

To more fully characterize the X-chromosomal content of RH 128, RH 128 DNA was PCR amplified using Alu-directed primer A-TC65N to generate human-specific products (Fig. 1). Ten randomly selected ethidium bromide-stained products were mapped by hybridization to Southern blots containing IP1 somatic cell hybridmapping-panel DNA. All 10 products hybridized to all of the mapping panel DNAs, including those containing only Xq (hybrids A48-1Fa and A63-1A) (data not shown). Together, these results indicated that RH 128 contained at least three distinct $\mathrm{X}$ chromosome fragments and, although RH 128 contained DNA markers spanning the IP1 X chromosome translocation break- 

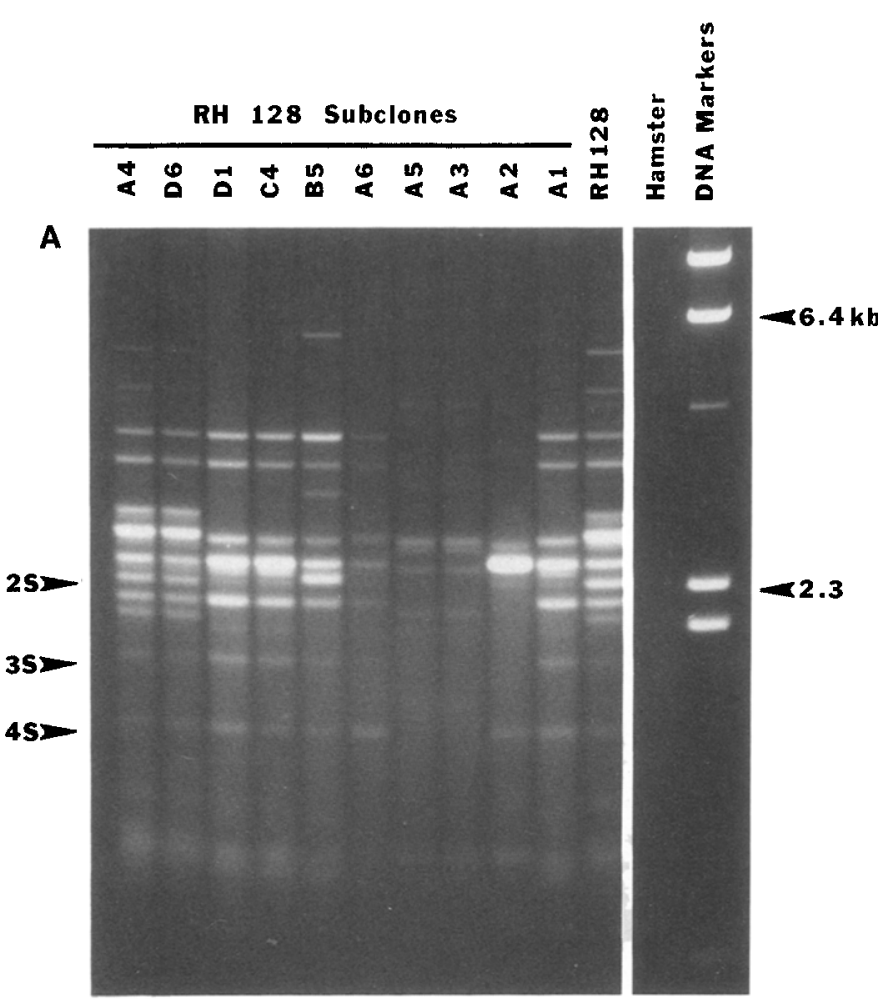

B

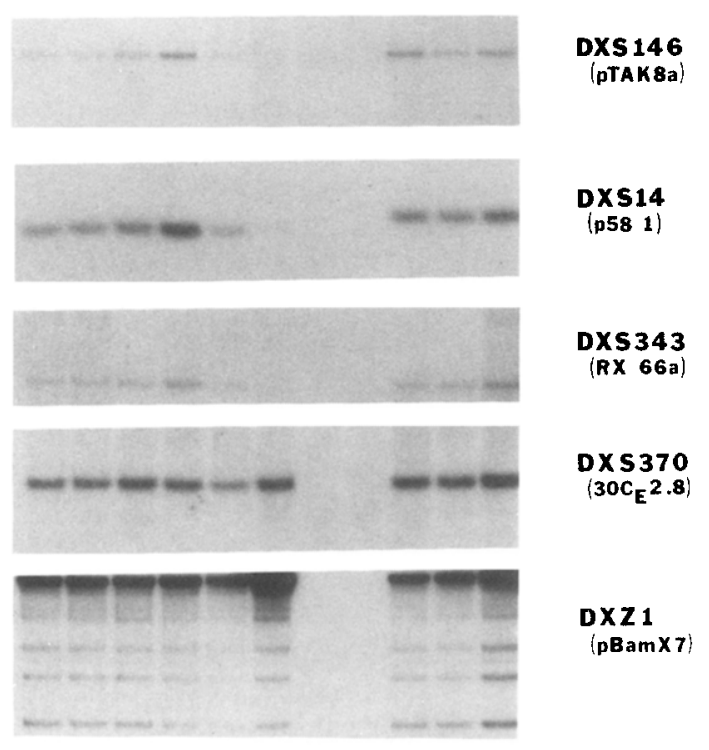

FIG. 1. Comparison of A-TC65N-primed PCR amplification products obtained from DNA isolated from a hamster cell line, RH 128, and 10 independently derived RH 128 subclones (clones A4-A1) electrophoresed in a $1.5 \%$ agarose gel (A), and autoradiograms of a membrane containing identically ordered HindIII-digested RH 128 and RH 128 subclone DNAs sequentially hybridized with DNA markers spanning the IP1 X-chromosomal translocation breakpoints (B). Compared to RH 128, subclones A4 and D6 yielded an identical pattern of PCR products; the other subclones yielded a reduced pattern, and subclone A2 yielded the fewest products (A). Eight subclones contained all five markers spanning the IP1 breakpoints; subclones A3 and A5 contained none of the markers (B). Three PCR products, $2 \mathrm{~S}, 3 \mathrm{~S}$, and $4 \mathrm{~S}$ (arrows) were restricted to those $\mathrm{RHs}$ containing the DNA markers (A). points, most RH 128 IRS-PCR products were Xq in origin.

We hypothesized that, for a radiation hybrid containing multiple human chromosome fragments, fragments integrated within different hamster chromosomes would segregate independently during passage. By inference, this suggested that, by isolating and characterizing a number of RH 128 subclones, it would be possible to (a) identify "enriched" subclones that nonselectively retained DNA markers in the vicinity of the IP1 locus while losing other human fragments present in the parental RH, (b) determine whether DNA markers consistently cosegregated as expected for contiguous markers, and (c) construct a RH subclone mapping panel. To facilitate the isolation of additional DNA markers in the vicinity of the IP1 locus, we tested this hypothesis by isolating 24 independent $\mathrm{RH} 128$ subclones; 10 subclones were stable enough to isolate DNA.

\section{Comparative Analysis and Regional Assignment of IRS-PCR Radiation Hybrid Products}

Ten RH 128 subclones were characterized by Southern hybridization and IRS-PCR amplification using $A l u$ and L1Hs-directed primers. Using primer A-TC65N, RH 128 DNA yielded at least 30 distinct ethidium bromide-stained amplification products ranging from 6.4 to $0.6 \mathrm{~kb}$ in size; no products resulted from the amplification of hamster DNA, indicating that the primers were human-specific (Fig. 1). RH 128 and subclones A4 and D6 yielded an identical pattern of products. Eight subclones yielded a reduced but similar pattern of products, which varied by the presence or absence of a small number of specific products. Several subclones (D1, C4, and A1; A5 and A3) yielded apparently identical patterns; subclone A2 yielded the most reduced pattern (Fig. 1). Similar results were obtained using primers A-517N and L1HsN (data not shown). These results demonstrated that the IRS-PCR amplifications were reproducible, distinctive, and specific and suggested that, compared to RH 128, subclones yielding a reduced pattern of amplification products contained fewer X-chromosomal fragments.

To identify RH 128 subclones containing DNA fragments spanning the IP1 breakpoints, probes mapped to regions proximal ( $\mathrm{pBamX} 7$ ), distal (pTAK8a), and between (p58-1, RX-66a, 30C $\mathrm{C}_{\mathrm{E}} 2.8$ ) IP1 X-chromosomal translocation breakpoints were hybridized to hybrid DNA. Eight subclones contained all five markers; subclones A3 and A5 contained none of the markers (Fig. 1). The observed cosegregation of DNA markers suggested that all five markers were contained on a single X chromosome fragment and implied that amplification products derived from this fragment would exhibit the same pattern of distribution within RH 128 subclone DNA.

Eleven distinct ethidium bromide-stained IRS-PCR amplification products were observed to be distributed in a pattern identical to the DNA markers spanning the IP1 breakpoints; these included A-TC65N-primed products $2 \mathrm{~S}, 3 \mathrm{~S}$, and $4 \mathrm{~S}$ (Fig. 1) and $2 \mathrm{~A}-517 \mathrm{~N}$ and $6 \mathrm{~L} 1 \mathrm{Hs}-$ 


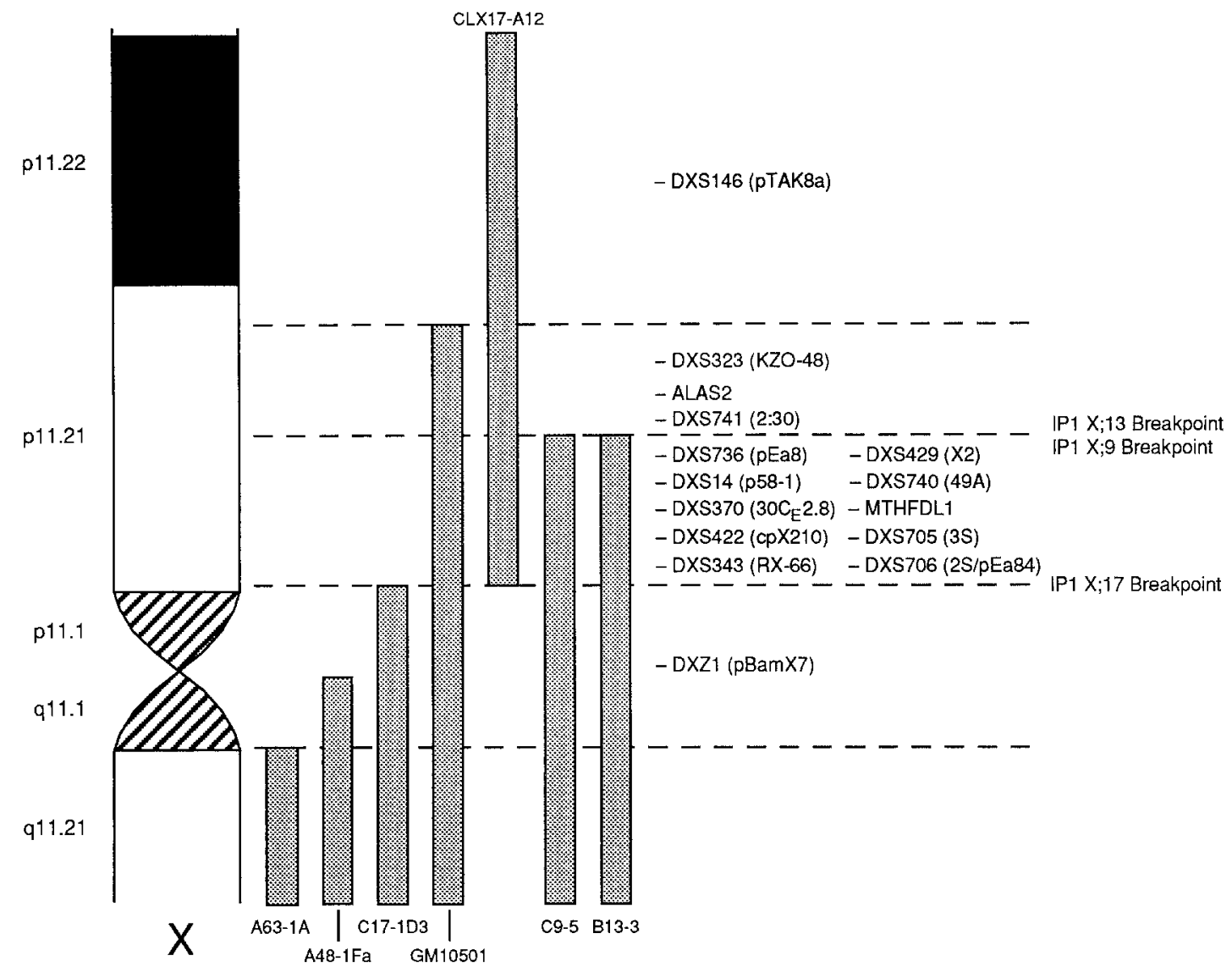

FIG. 2. Idiogram of GTG-banding patterns of the pericentric portion of a prometaphase human X chromosome (ISCN 1985). Bars indicate the $\mathrm{X}$-chromosomal regions present in specific somatic cell hybrids; the exact location of the IP1 X;17 X-chromosomal translocation breakpoint in relation to the Xcen has not been determined (Gorski et al., 1991). X-chromosomal loci found to be in the vicinity of the IP1 locus are shown in their assigned regions: 10 DNA sequences map to a region between IP1 X-chromosomal breakpoints; 3 DNA sequences map to a region distal to the X;13 and X;9 IP1 breakpoints and proximal to the GM10501 breakpoint within Xp11.21; and no loci have been assigned to the potential region between the IP1 X;9 and X;13 breakpoints. The regional assignments of MTHFDL1 (Rozen et al., 1989; Italiano et al., 1991), DXS705, DXS706, and DXS736 are based on mapping data reported in the present work; the regional assignment of DXS741 is based on mapping data reported in a companion paper (Gorski et al., 1992); and the other loci have been previously mapped (Gorski et al., 1991; Lafreniere et al., 1991; Cotter et al., 1992).

primed products (data not shown). To map these products to a specific X-chromosomal region, the 11 amplification products were isolated from gels and reamplified, and low-copy restriction fragments derived from the products were used as probes to hybridize to IP1 somatic cell hybrid-mapping-panel DNA. As shown schematically in Fig. 2, products $3 \mathrm{~S}$ and $2 \mathrm{~S}$ mapped to a region between IP1 X chromosome translocation breakpoints. Of the remaining 9 products, 1 mapped to Xq, 2 mapped distal to the GM10501 breakpoint on Xp, and 1 was autosomal; 2 products failed to reamplify and 3 were repetitive (data not shown).

Having isolated PCR products that mapped to a region of interest, we sought to modify this strategy to isolate additional products not identified by ethidium bromide staining. For this purpose, a plasmid library that contained the A-TC65N-primed amplification products of subclone A2 DNA was constructed; 96 recombinant clones were randomly selected, reamplified, and fingerprinted by restriction enzyme digestion. Most products (62 of $95 ; 65 \%$ ) were identical and corresponded to the intense $2.4-\mathrm{kb}$ ethidium bromide-stained amplification product seen in the amplified products of subclone A2 DNA (Fig. 1). By fingerprinting, 14 discrete amplification products were identified; 1 product, $\mathrm{pEa} 84$, was found to be identical to the previously isolated product $2 \mathrm{~S}$ (data not shown). To identify products exhibiting a distribution pattern matching that of the DNA markers spanning the IP1 breakpoints, each of the remaining 13 unique products was used as probe and hybridized to membranes containing the PCR products of A-TC65N-primed RH 128 subclone DNA; 8 products showed the desired hybridization pattern and hybridized to an identically sized product present in all of the subclone DNAs except subclone A3 (Fig. 3). By comparison, only 6 of 41 randomly selected A-TC65N-primed RH 128 amplification products yielded the same pattern of distribution (data not shown). Used as a probe and hybridized to IP1 somatic cell hybrid-mapping-panel DNA, product $\mathrm{pEa} 8$ mapped to the region between IP1 $\mathrm{X}$ chromosome translocation breakpoints (Figs. 2 and 3); 4 products mapped to $\mathrm{Xp}$ distal to the GM10501 breakpoint, and 3 were repetitive (data not shown). The localization of the isolated DNA markers, relative to 
A
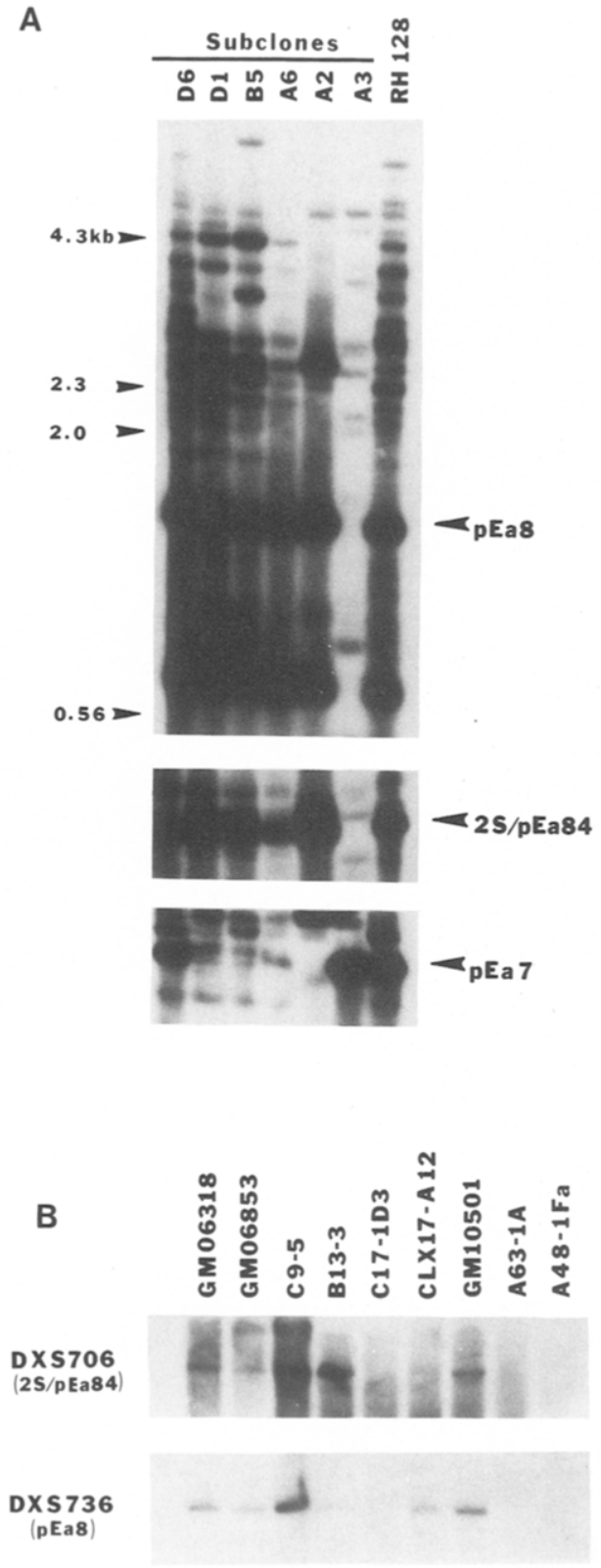

FIG. 3. Amplification products pEa8, 2S/pEa84, and pEa7 sequentially hybridized to $200 \mathrm{ng}$ of A-TC65N-primed $\mathrm{RH} 128$ subclone DNA amplification products (A) and HindIII-digested IP1 somatic cell hybrid mapping panel DNA (B). Although each probe hybridized to multiple amplification products, the observed hybridization pattern was probe-specific and each probe preferential hybridized to an identical-sized product (arrows). The hybridization pattern of probes $\mathrm{pEa} 8$ and $2 \mathrm{~S} / \mathrm{pEa} 84$ matched that of the DNA markers mapped to the region between IP1 breakpoints; even upon overexposure, as opposed to probe $\mathrm{pEa} 7$, neither $\mathrm{pEa} 8$ nor $2 \mathrm{~S} / \mathrm{pEa} 84$ detected a like-sized product in subclone A3 DNA (A). Probes pEa8 (DXS736) and 2S/pEa84 (DXS706) had identical patterns of hybridization to IP1 somatic cell hybrid mapping panel DNA; both mapped to the same region between IP1 X-chromosomal translocation breakpoints (B).

others mapped in the vicinity of the IP1 breakpoints, is summarized schematically in Fig. 2.

Physical Mapping of IRS-PCR Amplification Products

PFGE analyses were performed to better define the region between IP1 X chromosome translocation break- points and localize newly isolated DNA markers relative to those previously mapped; three probes could be tentatively overlapped by these analyses (Fig. 4). Probes cpX210 and MTHFDL1 detected a superimposable 660kb SfiI fragment; probes MTHFDL1 and 3S detected superimposable $1200-\mathrm{kb} S f i \mathrm{I}$ fragments, and 1300- to $1600-\mathrm{kb}$ SacII fragments; and probes cpX210 and 3S failed to detect a common restriction fragment. These results tentatively place probes cpX210 and MTHFDL1 within $660 \mathrm{~kb}$ and probes MTHFDL1 and 3S within $1200 \mathrm{~kb}$. Probe cpX210 was previously mapped to within $120 \mathrm{~kb}$ of probe p58-1 (Gorski et al., 1991); probe p58-1 failed to detect a restriction fragment common to MTHFDL1 and 3S (data not shown). These preliminary data suggest the locus order: DXS14-DXS422MTHFDL1-DXS705; this order requires confirmation by YAC cloning or additional PFGE studies.

Pulsed-field blots are extremely sensitive to repetitive sequences, more so than Southern blots; even with the use of probe competition conditions (Patel et al., 1991), probes derived from products $2 \mathrm{~S} / \mathrm{pEa} 84$ and $\mathrm{pEa} 8$ were found to be too repetitive to be used as probes for PFGE blots (data not shown). Probe 3S was used for a PFGE analysis of somatic cell hybrids containing IP1 derivative chromosomes; hybridized to PFGE blots containing EagI, SacII, and SfiI-digested hybrid C9-5, B13-3, CLX17-A12, and GM06318 DNAs, probe 3S detected restriction fragments of apparently identical size (data not shown). The evident uniformity of restriction fragments detected suggests that these restriction fragments have not been rearranged and implies that the IP1 Xchromosomal translocation breakpoints are located outside the region analyzed.

\section{DISCUSSION}

This study demonstrates an approach for rapidly isolating region-specific DNA markers from a $\mathrm{RH}$ containing multiple human chromosome fragments. The parental RH used in this study was round to contain at least three human X chromosome fragments, including a set of DNA markers spanning a region of interest within Xp11.21. To facilitate the mapping of DNA markers, we constructed a hybrid mapping panel composed of multiple, discrete subclones derived from a single parental RH. This hybrid panel was used to (a) identify particular subclones which contained the region of interest and yielded a reduced number of amplified products (and presumably contained a reduced number of $\mathrm{X}$ chromosome fragments) and (b) construct a mapping panel to assist in identifying regional DNA markers. Human-specific DNA markers were isolated from RH DNA by IRS-PCR amplification; products with the same pattern of distribution as previously mapped IP1 markers were tentatively identified as region-specific DNA markers. Using this approach, we have isolated three different PCR products that map to a region between IP1 X chromosome translocation breakpoints. 


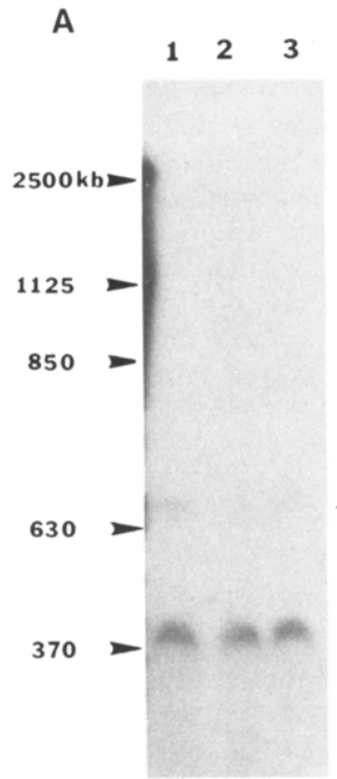

cpX210

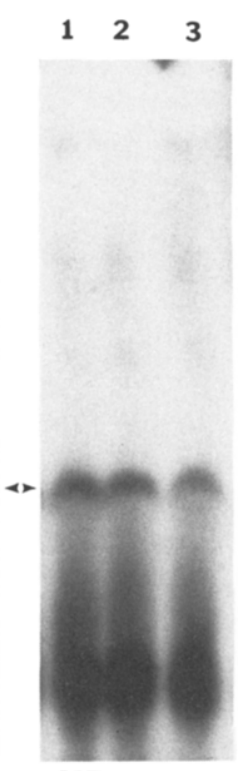

MTHFDL1

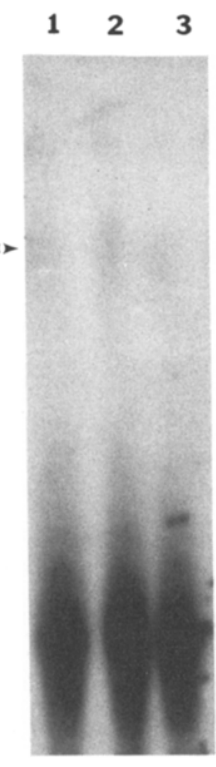

35

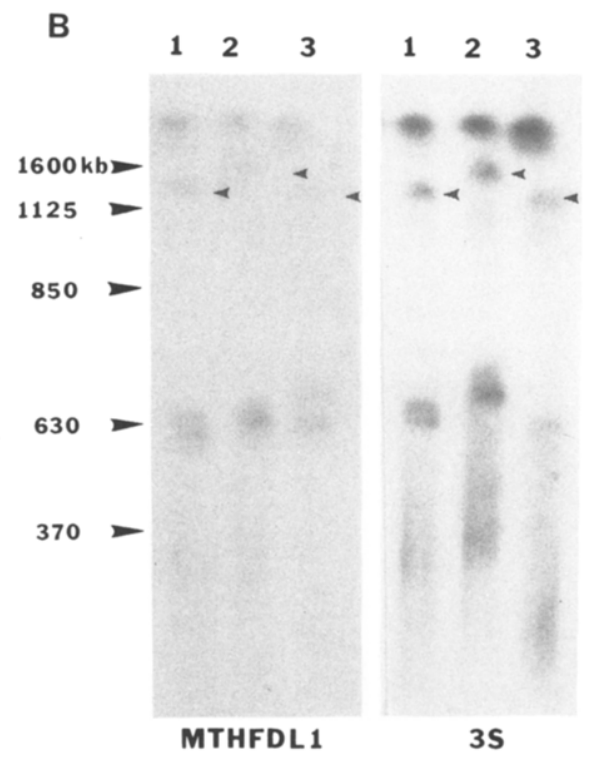

FIG. 4. Southern blot analysis of somatic cell hybrid DNA partially digested with either Sfi (A) or SacII (B); the same filters were sequentially hybridized with probes cpX210, MTHFDL1, and 3S. DNA was fractionated by CHEF electrophoresis in $1.0 \%$ agarose (0.5 $\times$ TBE) using $200 \mathrm{~V}$ at $14^{\circ} \mathrm{C}$; switch times were $60 \mathrm{~s}$ for $20 \mathrm{~h}$ and $120 \mathrm{~s}$ for $12 \mathrm{~h}$ (A) and $60 \mathrm{~s}$ for $15 \mathrm{~h}$ and $90 \mathrm{~s}$ for $9 \mathrm{~h}$ (B). For Sfi digests, hybrid GM06318 DNA was digested with $30 \mathrm{U}$ (lane 1), $15 \mathrm{U}$ (lane 2), and $5 \mathrm{U}$ (lane 3); for SacII digests, hybrid C9-5 (lane 1), B13-3 (lane 2), and CLX17-A12 (lane 3) DNAs were digested with $30 \mathrm{U}$. Probe cpX210 detected 400- and 660-kb SfI fragments; probe MTHFDL1 detected 260-, 660-, and $1200-\mathrm{kb}$ S f $\mathrm{I}$ I fragments, and 630- to $660-\mathrm{kb}$ and 1300- to 1600-kb SacII fragments; and probe 3S detected $340-$ and $1200-\mathrm{kb}$ S $f$ I fragments, and 660 - to $680-\mathrm{kb}$ and 1300 - to $1600-\mathrm{kb}$ SacII fragments. Arrows point to restriction fragments corecognized by different probes when autoradiograms are superimposed. The different SacII fragment sizes observed in hybrid C9-5 and B13-3 DNA were not present on other SacII blots and probably represent artifactual differences in quantities of DNA loaded; the partially digested SacII fragments detected by MTHFDL1 and 3S are superimposable.

It can be expected that $\mathrm{RHs}$ will have different attributes affecting the ease with which each can be used to construct a hybrid subclone mapping panel; the recovery of region-specific DNA markers from a $\mathrm{RH}$ has been hampered by the presence of additional fragments not detected by preliminary hybridization analyses (Benham and Rowe, 1992). The strategy we describe, however, should be generally applicable to other situations in which RHs contain a particular region of interest. RHs have been nonselectively constructed for a relatively large number of human chromosomes including $\mathrm{X}, 4,5,6,9,10,11,12,16$, and 21 (Benham et al., 1989; Ceccherini et al., 1989; Cox et al., 1989; Brooks-Wilson et al., 1990; Glaser et al., 1990; Florian et al., 1991; Ragoussis et al., 1991; Thomas, 1991; Zoghbi et al., 1991; Sinke et al., 1992); the use of $\mathrm{RH}$ subclones to assemble hybrid mapping panels may extend the use of existing $\mathrm{RHs}$ and provide additional hybrids for comparative mapping and subcloning.

Our present data do not provide an estimate of the total number of potential IRS-PCR products contained within the region between IP1 X-chromosomal translocation breakpoints; however, our results suggest that a more intensive effort would result in the isolation of additional region-specific DNA markers. Presently, we have isolated approximately one region-specific DNA marker per $800 \mathrm{~kb}$ of genomic DNA. This cloning efficiency compares favorably to other, more labor intensive techniques, such as chromosome microdissection (Ludecke et al., 1989), PERT cloning (Nussbaum et al., 1987), and coincidental cloning (Aslanidis and de Jong, 1991). In addition, this achieved density of DNA markers is appropriate for the initiation of additional molecular studies including PFGE mapping, radiation hybrid mapping (Cox et al., 1990), fluorescence in situ hybridization analysis (Trask et al., 1991), the isolation of overlapping genomic clones in yeast artificial chromosomes (Schlessinger et al., 1991), and the isolation of sequence tagged sites (Olsen et al., 1989). A total of 10 DNA sequences have now been mapped to a region between IP1 X-chromosomal translocation breakpoints. Together, these sequences provide a starting point for identifying overlapping genomic sequences spanning the IP1 breakpoints; the availability of IP1 translocation breakpoints should assist the molecular analysis of this locus.

\section{ACKNOWLEDGMENTS}

We thank D. Barker, G. Bruns, K. Davies, T. Kruse, R. Rozen, P. Szabo, and H. Willard, for cloned human DNA probes; $H$. Willard for somatic cell hybrids A48-1Fa and A63-1A; and D. Voss for assisting in preparing the manuscript. Cell lines GM06853, GM10501, and GM06318 were obtained from the NIGMS Human Genetic Mutant Cell Repository, Coriell Institute of Medical Research (Camden, NJ). This work was supported in part by March of Dimes-Birth Defects Foundation Basil O'Conner Research Starter Grant 5-165, March of 
Dimes-Birth Defects Foundation Basic Science Grant 1-91-176, and National Institutes of Health (NIH) Grants HD-23768 and NS-30771 to J.L.G., and NIH Training Grant NIH-5-T32-GM07544-11 to E.N.B.

\section{REFERENCES}

Aslanidis, C., and de Jong, P. J. (1991). Coincidence cloning of Alu PCR products. Proc. Natl. Acad. Sci. USA 88: 6765-6769.

Benham, F., Hart, K., Crolla, J., Bobrow, M., Francavilla, M., and Goodfellow, P. N. (1989). A method for generating hybrids containing nonselected fragments of human chromosomes. Genomics 4: 509-517.

Benham, F., and Rowe, P. (1992). Use of Alu-PCR to characterize hybrids containing multiple fragments and to generate $\mathrm{Xp} 21.3$ p22.2 markers. Genomics 12: $368-376$.

Brooks-Wilson, A. R., Goodfellow, P. N., Povey, S., Nevanlinna H. A., deJong, P. J., and Goodfellow, P. J. (1990). Rapid cloning and characterization of new chromosome 10 DNA markers by Alu element-mediated PCR. Genomics 7: 614-620.

Cannizzaro, L. A., and Hecht, F. (1987). Gene for incontinentia pigmenti maps to band $\mathrm{Xp} 11.21$ with an $(\mathrm{X} ; 10)(\mathrm{p} 11 ; \mathrm{q} 22)$ translocation. Clin. Genet. 32: 66-69.

Ceccherini, I., Persici, P., Vitale, E., Rocchi, M., Breuning, M., Frischauf, A., Hyland, V., Germino, G., Reeders, S., and Romeo, G. (1989). Radiation hybrids generated for the construction of a map of chromosome 16. Cytogenet. Cell Genet. 57: 975 .

Chu, G., Vollrath, D., and Davis, R. W. (1986). Separation of large DNA molecules by contour-clamped homogeneous electric fields. Science 234: 1582-1585.

Cotter, P. D., Willard, H. F., Gorski, J. L., and Bishop, D. F. (1992). Assignment of human erythroid delta-aminolevulinate synthase (ALAS2) to a distal subregion of band Xp11.21 by PCR analysis of somatic cell hybrids containing X; autosome translocations. Genomics 13: 211-212.

Cox, D. R., Pritchard, C. A., Uglum, E., Casher, D., Kobori, J., and Myers, R. M. (1989). Segregation of the Huntington disease region of human chromosome 4 in a somatic cell hybrid. Genomics 4: 397407.

Cox, D. R., Burmeister, M., Price, E. R., Kim, S., and Myers, R. M. (1990). Radiation hybrid mapping: A somatic cell genetic method for constructing high-resolution maps of mammalian chromosomes. Science 250: 245-250.

Crolla, J. A., Gilgenkrantz, S., de Grouchy, J., Kajii, T., and Bobrow, M. (1989). Incontinentia pigmenti and X-autosome translocations: Non-isotopic in situ hybridization with an X-centromere-specific probe (pSV2X5) reveals a possible X-centromeric breakpoint in one of five published cases. Hum. Genet. 81: 269-272.

Feinberg, A., and Vogelstein, B. (1983). A technique for radiolabeling DNA restriction endonuclease fragments to high specific activity. Anal. Biochem. 132: 6-13.

Florian, F., Hornigold, N., Griffen, S., Delhanty, J., Sefton, L., Abbott, C., Jones, C., Goodfellow, P. N., and Wolfe, J. (1991). The use of irradiation and fusion gene transfer (IFGT) hybrids to isolate DNA clones from human chromosome region 9q33-34. Somat. Cell Mol. Genet. 17: 445-453.

Gilgenkrantz, S., Tridon, P., Pinel-Briquel, N., Beurey, J., and Weber, M. (1985). Translocation $(\mathrm{X} ; 9)(\mathrm{p} 11 ; \mathrm{q} 34)$ in a girl with incontinentia pigmenti (IP): Implications for the regional assignment of the IP locus to Xp11. Ann. Genet. 28: 90-92.

Glaser, T., Rose, E., Morse, H., Housman, D., and Jones, C. (1990). A panel of irradiation-reduced hybrids selectively retaining human chromosome 11p13: Their structure and use to purify the WAGR gene complex. Genomics 6: 48-64.

Gorski, J. L., Stein, C. K., and Glover, T. W. (1989). A somatic cell hybrid panel to facilitate identification of DNA sequences in the vicinity of the incontinentia pigmenti locus (IP1). Cytogenet. Cell Genet. 52: 90-92.

Gorski, J. L., Burright, E. N., Harnden, C. E., Stein, C. K., Glover,
T. W., and Reyner, E. L. (1991). Localization of DNA sequences to a region within Xp11.21 between incontinentia pigmenti (IP1) Xchromosomal translocation breakpoints. Am. J. Hum. Genet. 48: $53-64$.

Gorski, J. L., Boehnke, M., Reyner, E. L., and Burright, E. N. (1992). A radiation hybrid map of the proximal short arm of the human $X$ chromosome spanning incontinentia pigmenti 1 (IP1) translocation breakpoints. Genomics 14: 657-665.

Goss, S. J., and Harris, H. (1975). New method for mapping genes in human chromosomes. Nature (London) 255: 680-683.

Harnden, D. G., and Klinger, H. P., Eds. ISCN, (1985). "An International System for Human Cytogenetic Nomenclature," published in collaboration with Cytogenet. Cell Genet., Karger, Basel.

Hodgson, S. V., Neville, B., Jones, R. W. A., Fear, C., and Bobrow, M. (1985). Two cases of X; autosome translocation in females with incontinentia pigmenti. Hum. Genet. 71: 231-234.

Italiano, C., John, S. W. M., Hum, D. W., Mackenzie, R. E., and Rozen, R. (1991). A pseudogene on the X chromosome for the human trifunctional enzyme MTHFD (methylenetetrahydrofolate dehydrogenase-methenyltetrahydrofolate cyclohydrolase-formyltetrahydrofolate synthetase). Genomics 10: 1073-1074.

Kajii, T., Tsukahara, M., Fukushima, Y., Hata, A., Matsuo, K., and Kuroki, Y. (1985). Translocation (X;13)(p11.21;q12.3) in a girl with incontinentia pigmenti and bilateral retinoblastoma. Ann. Genet. 28: 219-223.

Lafreniere, R. G., Brown, C. J., Powers, V. E., Carrel, L., Davies, K. E., Barker, D. F., and Willard, H. F. (1991). Physical mapping of 60 DNA markers in the p21.1-q21.3 region of the human X chromosome. Genomics 11: 352-363.

Ledbetter, S. A., Nelson, D. L., Warren, S. A., and Ledbetter, D. H. (1990). Rapid isolation of DNA probes within specific chromosome regions by interspersed repetitive sequences polymerase chain reaction. Genomics 6: $475-481$.

Ludecke, H.-J., Senger, G., Claussen, U., and Horsthemke, B. (1989). Cloning defined regions of the human genome by microdissection of banded chromosomes and enzymatic amplification. Nature (London) 338: 348-350.

Mahtani, M. M., and Willard, H. F. (1988). A primary genetic map of the pericentric region of the human $\mathrm{X}$ chromosome. Genomics 2: 294-301.

Maniatis, T., Fritsch, E. F., and Sambrook, J. (1982). "Molecular Cloning: A Laboratory Manual," Cold Spring Harbor Laboratory, Cold Spring Harbor, NY.

Nelson, D. L., Ledbetter, S. A., Corbo, L., Victoria, M. F., RamirezSolis, R., Webster, T. D., Ledbetter, D. H., and Caskey, T. (1989). Alu polymerase chain reaction: A method for rapid isolation of human-specific sequences from complex DNA sources. Proc. Natl. Acad. Sci. USA 86: 6686-6690.

Nussbaum, R. L., Lesko, J. G., Lewis, R. A., Ledbetter, S. A., and Ledbetter, D. H. (1987). Isolation of anonymous DNA sequences from within a submicroscopic $\mathrm{X}$ chromosomal deletion in a patient with choroideremia, deafness, and mental retardation. Proc. Natl. Acad. Sci. USA 84: 6521-6525.

Olsen, M., Hood, L., Cantor, C., and Botstein, D. (1989). A common language for physical mapping of the human genome. Science $\mathbf{2 4 5}$ : 1434-1435.

Patel, K., Cox, R., Shipley, J., Kiely, F., Frazer, K., Cox, D. R., Lehrach, H., and Sheer, D. (1991). A novel and rapid method for isolating sequences adjacent to rare cutting sites and their use in physical mapping. Nucleic Acids Res. 16: 4371-4375.

Ragoussis, J., Jones, T. A., Sheer, D., Shrimpton, A. E., Goodfellow, P. N., Trowsdale, J., and Ziegler, A. (1991). Isolation of probes specific to human chromosomal region 6p21 from immunoselected irradiation-fusion gene transfer hybrids. Genomics 10: 598-607.

Rozen, R., Barton, D., Du, J., Hum, D. W., MacKenzie, R. E., and Francke, U. (1989). Chromosomal localization of the gene for the human trifunctional enzyme, methylenetetrahydrofolate dehydroge- 
nase-methenyltetrahydrofolate cyclohydrolase-formyltetrahydrofolate synthetase. Am. J. Hum. Genet. 44: 781-786.

Schleif, R. F., and Wensink, P. C. (1981). "Practical Methods in Molecular Biology," Springer-Verlag, New York, NY.

Schlessinger, D., Little, R. D., Freije, D., Abidi, F., Zucchi, I., Porta, G., Pilia, G., Nagaraja, R., Johnson, S. K., Yoon, J-Y., Srivastava, A., Kere, J., Palmieri, G., Ciccodicola, A., Montanaro, V., Romano, G., Casamassimi, A., and D'Urso, M. (1991). Yeast artificial chromosome-based genome mapping: Some lessons from Xq24-q28. Genomics 11: 783-793.

Sealey, P. G., Whittaker, P. A., and Southern, E. M. (1985). Removal of repeated sequences from hybridization probes. Nucleic Acids Res. 13: 1905-1922.

Sinke, R. J., Suijkerbuijk, R. F., Herbergs, J., Janssen, H., Cassiman, J. J., and Geurts van Kessel, A. (1992). Generation of a panel of somatic cell hybrids containing fragments of human chromosome $12 \mathrm{p}$ by X-ray irradiation and cell fusion. Genomics 12: 206-213.

Thomas, H. (1991). Ph.D. thesis, University of London.

Trask, B. J., Massa, H., Kenwrick, S., and Gitschier, J. (1991). Mapping of human chromosome $\mathrm{Xq} 28$ by two-color fluorescence in situ hybridization of DNA sequences to interphase cell nuclei. $A m$. J. Hum. Genet. 48: 1-15.

Westerveld, A., Visser, R. P. L. S., Kahn, P. M., and Bootsma, D. (1971). Loss of human genetic markers in man-Chinese hamster ovary cells. Nature (New Biol.) 234: 20-22.

Zoghbi, H. Y., McCall, A. E., and LeBorgne-Demarquoy, F. (1991). Sixty-five radiation hybrids for the short arm of human chromo some 6: Their value as a mapping panel and as a source for rapid isolation of new probes using repeat element-mediated PCR. Genomics 9: $713-720$. 